\title{
Tumor de células germinativas de testículo simulando câncer de pâncreas
}

Testicular germ cell tumor mimicking pancreatic cancer

\author{
Carlos Eduardo Paiva', Lia Rachel Gaspari², Julio César Donato ${ }^{3}$, Odair Carlito Michelin ${ }^{4}$
}

\section{Resumo}

Durante as últimas duas décadas, os tumores de células germinativas de origem gonadal ou extragonadal se transformaram no modelo de tumor sólido curável, principalmente em função da boa sensibilidade à quimioterapia baseada em cisplatina. Em cerca de $90 \%$ dos casos, se apresentam com sintomas testiculares e nos casos restantes em função de metástases. Apresentamos um caso atípico que simulou inicialmente um câncer de pâncreas, atrasando o diagnóstico. Salientamos a importância de se pensar em tumor de células germinativas, principalmente em homens jovens com icterícia obstrutiva e massa em topografia de pâncreas, já que um linfonodo retroperitoneal metastático pode simular um tumor primário em pâncreas, tanto clinicamente como aos exames de imagem. Sabendo ser um câncer com tendência a rápido crescimento, mas curável em grande parte dos casos, o atraso no diagnóstico pode dificultar o tratamento de um paciente em condições inadequadas.

Palavras-chave: Germinoma; Neoplasias pancreáticas; Diagnóstico diferencial.

\section{Abstract}

In the last two decades, germ cell tumors (gonadal or extragonadal) have become the model of a curable solid tumor, especially because of their good sensitivity to cisplatinum-based chemotherapy. Some $90 \%$ of cases present testicular symptoms, and the remaining cases those from metastases. This study presents an atypical case that initially appeared to be pancreatic cancer, thus delaying diagnosis. The importance of considering germ cell tumors should be emphasized, mainly in young men with obstructive jaundice and a pancreatic mass, since retroperitoneal metastatic lymph nodes can simulate pancreatic tumor both clinically and radiographically. Most cases are potentially curable but grow rapidly, so late diagnosis can hinder treatment of patients under inadequate conditions.

Key words: Germinoma; Pancreatic neoplasms; Diagnosis differential.

\footnotetext{
Trabalho realizado na Seção Técnica de Quimioterapia da Faculdade de Medicina de Botucatu/ UNESP.

${ }^{1}$ Médico Residente do terceiro ano do programa de Residência Médica em Cancerologia Clínica pela Faculdade de Medicina de Botucatu, UNESP.

${ }^{2}$ Oncologista clínica da Seção de Quimioterapia do Hospital das Clínicas da Faculdade de Medicina de Botucatu, UNESP.

${ }^{3}$ Hematologista da Seção de Quimioterapia do Hospital das Clínicas da Faculdade de Medicina de Botucatu, UNESP.

${ }^{4}$ Professor Assistente, Doutor do Departamento de Clínica Médica e responsável pela Residência de Cancerologia Clínica da Faculdade de Medicina de Botucatu, UNESP.

Endereço para correspondência: C.E.P. Travessa Victor Pavan, 15, Jardim Paraíso I, Botucatu, São Paulo, Brasil. CEP:18600-000

E-mail: cepaiva@fmb.unesp.br.
} 


\section{INTRODUÇÃO}

Os tumores de células germinativas (TCG) acometem freqüentemente indivíduos jovens, brancos e têm tendência a crescimento rápido e comportamento agressivo. Podem ser gonadais ou extragonadais. São considerados curáveis mesmo quando metastáticos. Os TCG testiculares podem ser classificados como seminomatosos ou nãoseminomatosos, sendo que estes têm prognóstico pior. ${ }^{1}$ Geralmente, se apresentam com sintomas testiculares, porém, em cerca de $10 \%$ dos casos, com sintomas decorrentes de comprometimento metastático, principalmente dor abdominal e sintomas respiratórios. ${ }^{2}$ Em alguns casos, apresentam achados atípicos, o que pode dificultar o diagnóstico. ${ }^{3}$

Neste relato, será discutida a apresentação clínica dos TCG, enfatizando a possibilidade de apresentaçōes atípicas, como a de um linfonodo retroperitoneal metastático simulando um câncer de pâncreas.

\section{RELATO DO CASO}

JLFJ, masculino, branco, 26 anos, casado, servente de pedreiro, natural e procedente de Itaí-SP, deu entrada no Pronto Socorro do Hospital das Clínicas da Faculdade de Medicina de Botucatu (FMB) no dia 10/ $12 / 2004$, referindo dor em faixa em abdome superior há quatro meses, perda de 10 quilos no mesmo período, icterícia há dois meses e aumento abdominal há 15 dias. Negava qualquer comorbidade, uso crônico de medicaçôes ou internações prévias. Referia história de câncer em avô paterno. Tabagista há 20 anos de um maço/dia. Bebia $400 \mathrm{ml}$ de cachaça três vezes por semana, há cerca de dez anos. Ao exame físico, mostravase emagrecido, performance status de 2, descorado $(+1$ 4), desidratado (+/4), ictérico (++/4) e afebril. O exame cardiopulmonar foi normal. O exame do abdome evidenciou massa volumosa, dura, pouco dolorosa, em região superior do abdome.

Os exames laboratoriais sugeriram síndrome colestática, mostrando bilirrubinas totais: $5,2 \mathrm{mg} / \mathrm{dL}$ (valores normais entre 0,2 a $1,3 \mathrm{mg} / \mathrm{dL}$ ), bilirrubinas indiretas: $0,9 \mathrm{mg} / \mathrm{dL}(0$ a $1,1 \mathrm{mg} / \mathrm{dL})$, bilirrubinas conjugadas: $4,3 \mathrm{mg} / \mathrm{dL}(0$ a $0,3 \mathrm{mg} / \mathrm{dL})$, AST/TGO: 110 U/L (17 a 59 U/L), ALT/TGP: 48 U/L (21 a 75 U/L), fosfatase alcalina: $159 \mathrm{U} / \mathrm{L}$ (38 a $126 \mathrm{U} / \mathrm{L}), \mathrm{gGT}: 176$ U/L (15 a $73 \mathrm{U} / \mathrm{L})$ e amilase normal. A tomografia computadorizada (TC) de abdome mostrou massa hipodensa em topografia de pâncreas, de aproximadamente $13 \mathrm{~cm}$ em seu maior diâmetro e várias imagens hipodensas compatíveis com metástases em fígado (figuras 1A e 1B). Não havia dilatação de vias

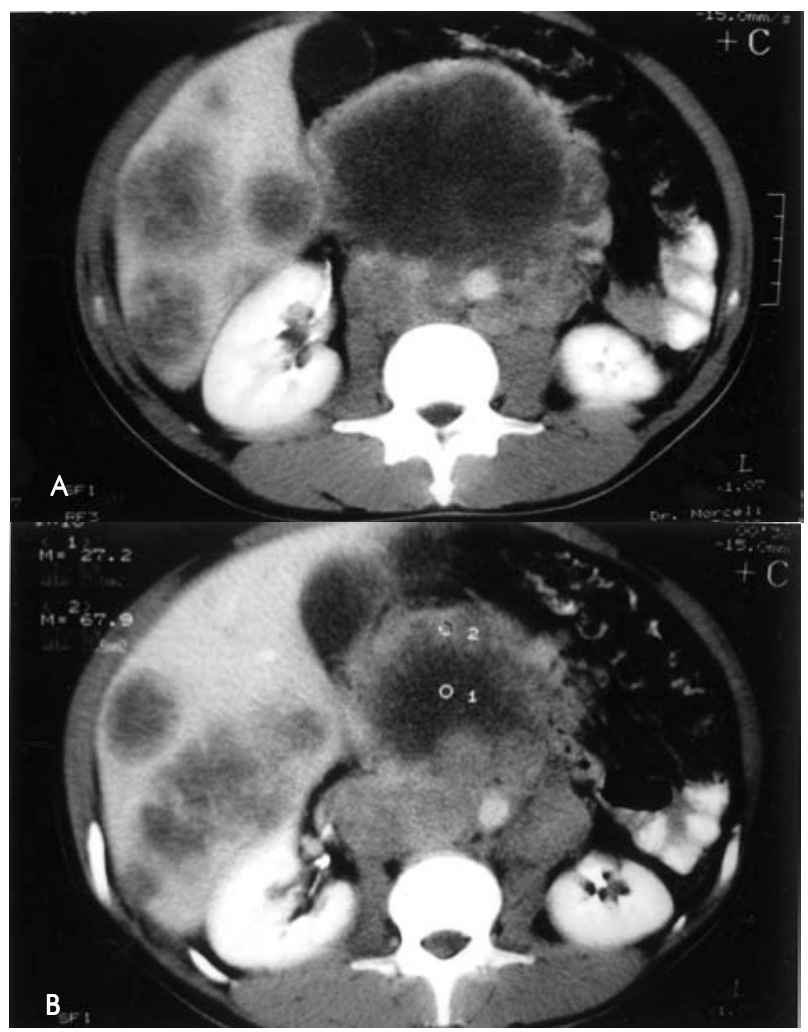

Figura 1. A- Massa em topografia de pâncreas com densidade líquida e leões hipodensas bem definidas em parênquima hepático. B- Massa hipodensa em topografia de pâncreas com realce periférico pelo contraste endovenoso e lesões hepáticas hipodensas e bem definidas

biliares à TC de abdome. O paciente foi internado para investigação diagnóstica. Foi submetido à biópsia da massa que mostrou tecido necrótico, possibilitando definir-se pelo tratamento apenas da neoplasia maligna, sem diagnóstico histopatológico específico. A equipe de oncologia clínica do referido hospital foi solicitada para avaliar o paciente no dia 26/12/2004, quando o mesmo apresentava-se com performance status de 3 , ictérico $(+++/ 4)$, com distensão abdominal importante, parada de eliminação de gases e fezes e murmúrio vesicular diminuído bilateralmente, principalmente em hemitórax direito. Estava recebendo cuidados para oclusão intestinal. Palpou-se, nesta ocasião, o testículo esquerdo endurecido, indolor, de volume normal. Uma ultra-sonografia (US) escrotal mostrou testículo esquerdo de dimensōes normais, porém ecotextura heterogênea e imagem nodular bem vascularizada, heterogênea, de $2,5 \times 1,7 \times 2,3 \mathrm{~cm}$, em seu terço inferior (figura 2). Foram iniciadas medidas profiláticas para síndrome de lise tumoral e solicitados exames para estadiamento. A TC de tórax mostrou inúmeros nódulos metastáticos pulmonares bilateralmente e os marcadores tumorais definiram o diagnóstico com ß-HCG de 400.809 mUI/ $\mathrm{mL}(<5 \mathrm{mUI} / \mathrm{mL})$, alfa-feto proteína de $842 \mathrm{ng} / \mathrm{mL}(<7$ 
$\mathrm{ng} / \mathrm{mL}$ ) e desidrogenase lática (DHL) de $7000 \mathrm{U} / \mathrm{L}$. Mesmo sem diagnóstico histopatológico, frente ao quadro clínico e marcadores tumorais elevados, fez-se o diagnóstico de tumor de células germinativas de testículo, estadiado como TxN3M1S3, estádio IIIC, alto risco. O tratamento quimioterápico foi realizado de imediato, frente à impossibilidade de realizar a orquiectomia, devido às precárias condições clínicas do paciente. Foi programado protocolo BEP, modificado em função das condições clínicas ruins do paciente e função hepática alterada. No primeiro dia (D1) da quimioterapia, o paciente apresentou hemorragia digestiva alta em pequena quantidade. No D2 da quimioterapia, apresentou hiperuricemia e hiperfosfatemia. Foi abortado o primeiro ciclo no D3 (programado até D5) em função de insuficiência renal. No D7 da quimioterapia, o paciente apresentou novo aumento de creatinina, após dois dias de melhora, quando se diagnosticou infecção do trato urinário. No D9, apresentou piora importante e súbita da dor abdominal, além de melena, evoluindo para óbito após período de hipotensão arterial. A família do paciente não permitiu a realização de necropsia para avaliação histopatológica, porém, posteriormente, consentiu a publicação desse relato, assinando o termo de consentimento livre e esclarecido. Este trabalho foi aprovado pelo Comitê de Ética em Pesquisa da FMB.

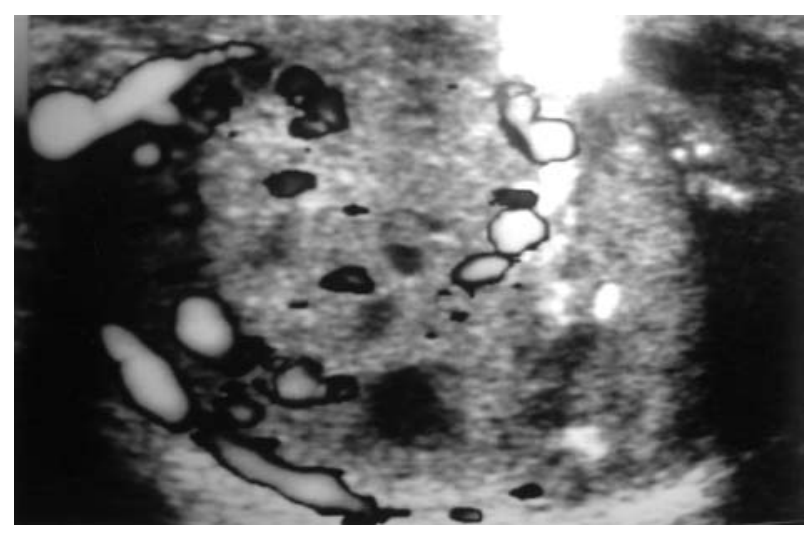

Figura 2. Ultra-sonografia escrotal mostrando testículo esquerdo com estrutura heterogênea e imagem nodular, bem vascularizada ao doppler, medindo $2,5 \times 1,7 \times 2,3 \mathrm{~cm}$, em seu terço inferior

\section{DISCUSSÃO}

O tumor de células germinativas é a malignidade sólida mais comum em homens entre 15 e 34 anos. ${ }^{1,4}$ A maioria dos pacientes se apresenta com tumor primário em testículo. Em uma minoria de pacientes, a doença é extragonadal, sendo que em um terço destes parece haver regressão do tumor testicular sem tratamento, mostrando-se como tecido cicatricial, sem tumor viável e indicando a presença anterior de um tumor que regrediu (fenômeno "burned-out"). ${ }^{4}$ Este caso traz, como particularidade, a apresentação metastática volumosa com imagem de tumor testicular pequeno.

O diagnóstico de um TCG testicular metastático pode se basear na combinação de variáveis clínicas e marcadores tumorais elevados ( $ß-\mathrm{HCG}$ e alfa-feto proteína), principalmente em casos de sintomas abdominais e pulmonares agudos, secundários a metástases, com risco iminente de vida, casos estes em que a quimioterapia tem indicação de urgência. ${ }^{5} \mathrm{~A}$ maioria dos casos de TCG testiculares nãoseminomatosos tem bom prognóstico, porém pacientes com níveis séricos de ß-HCG maiores que 25.000 parecem ter prognóstico pior. Esses pacientes se apresentam, muitas vezes, com a "síndrome do coriocarcinoma", isto é, doença avançada, rapidamente progressiva, com freqüentes complicações hepáticas, pulmonares e cerebrais, e resposta ruim à quimioterapia padrão com cisplatina. ${ }^{6}$ No caso aqui apresentado, o paciente foi submetido à quimioterapia e apresentava ao diagnóstico níveis séricos de B-HCG de cerca de $400 \mathrm{mil} \mathrm{mUI/ml}$.

Cerca de 10 a $14 \%$ dos pacientes se apresentam inicialmente com doença metastática. Dentre estas apresentaçôes, se incluem massa abdominal, adenopatia supra-clavicular, sintomas respiratórios, anorexia, náuseas, vômitos, dor lombar baixa e edema de membros inferiores. $^{2}$ Dieckmann et al. encontraram $12 \%$ dos TCG se apresentando com sintomas extragonadais, sendo que, destes, $47 \%$ apresentaram dor abdominal e $29 \%$ sintomas respiratórios. ${ }^{3}$ Wehrschut et al. relataram um caso de seminoma de testículo direito cuja metástase em retroperitôneo simulou um câncer de pâncreas, em função de sinais clínicos de doença pancreática avançada (icterícia, perda de peso e dor abdominal) e imagem de tumor em cabeça de pâncreas à TC. ${ }^{7}$ Wang et al. publicaram um caso com apresentação clínica semelhante, cujo diagnóstico de coriocarcinoma metastático para pâncreas se deu após procedimento de pancreatoduodenectomia. ${ }^{8}$ No presente caso, o paciente se apresentou com dor abdominal irradiada para as costas, emagrecimento, icterícia obstrutiva e imagem compatível com tumor cístico de pâncreas.

Dos TCG de testículo, apenas 5\% apresentam acometimento gastrointestinal, sendo que Rosemblatt et al. relataram um caso que se apresentou inicialmente com hemorragia digestiva alta por tumor testicular com componente de coriocarcinoma metastático para duodeno. ${ }^{9}$ Os coriocarcinomas detêm característica peculiar de sangramento, fato que pode ocorrer logo após início do tratamento. No relato em questão, o 
paciente apresentou hemorragia digestiva alta perceptível clinicamente, em duas ocasiōes, logo após o início da quimioterapia e sete dias após.

Bosl et al. associaram o atraso no diagnóstico com apresentaçōes mais avançadas de TCG, sendo que Moul et al. mostraram que isto alterava o prognóstico, principalmente na era pré-cisplatina (1970 a 1978). ${ }^{10,11}$ Dieckmann et al. mostraram maior mortalidade em TCG que se apresentaram com sintomas atípicos (35\%) em relação aos com sintomas típicos $(6 \%) .{ }^{3}$ Os TCG são curáveis mesmo quando metastáticos, fato bem diferente dos cânceres de pâncreas, que carregam um prognóstico em geral ruim, com poucas opções terapêuticas efetivas.

Apesar de ser peça importante no exame clínico de qualquer paciente, o exame físico dos testículos é comumente relegado à avaliação do urologista. Pacientes com TCG podem apresentar-se de maneira atípica, sendo que este diagnóstico deve ser suspeitado principalmente em pacientes jovens, com tumores em linha média e de sítio primário desconhecido. Acrescentamos a possibilidade de metástases retroperitoneais poderem simular tumores pancreáticos, clinicamente e aos exames de imagem, sendo que a solicitação de marcadores tumorais (B-HCG e alfafetoproteína) pode ajudar no diagnóstico.

\section{REFERÊNCIAS BIBLIOGRÁFICAS}

1. Bosl GJ, Bajorin DF, Sheinfeld J. Cancer of the testis. In: DeVita VT Jr, Hellman S, Rosemberg SA, editors. Cancer: Principles and Practice of Oncology. 7 th ed. Philadelphia, PA: Lippincott Williams \& Wilkins; 2005. p. 1269-93.
2. Glass MA, Meacham RB. Typical and Atypical Presentations of Testicular Carcinoma. J Diag Med Sonography. 1997;13(1):17-21.

3. Dieckmann KP, Krain J, Gottschalk W, Buttner P. Atypical symptoms in patients with germinal testicular tumors. Urologe A. 1994 ; 33(4):325-30.

4. Schmoll HJ, Souchon R, Krege S, Albers P, Beyer J, Kollmannsberger $\mathrm{C}$, et al. European consensus on diagnosis and treatment of germ cell cancer: a report of the European Germ Cell Consensus Group (EGCCCG). Ann Oncol. 2004; 15:1377-99.

5. Geldart TR, Simmonds PD, Mead GM. Orchidectomy after chemotherapy for patients metastatic testicular germ cell cancer. BJU Int. 2002 Sep;90(4):451-55.

6. McKendrick JJ, Theaker J, Mead GM. Nonseminomatous germ cell tumor with very high serum human chorionic gonadotropin. Cancer. 1991;67(3):684-9.

7. Wehrschutz M, Stoger H, Ploner F, Hofmann G, Wolf G, Hofler G, et al. Seminoma Metastases Mimicking Primary Pancreatic Cancer. Onkologie. 2002; 25(4):371-73.

8. Wang L, Pitman M, Castillo CF, Dal Cin P, Oliva E. Choriocarcinoma involving the pancreas as first manifestation of a metastatic regressing mixed testicular germ cell tumor. Mod Pathol. 2004;17(12):1573-80.

9. Rosemblatt GS, Walsh CJ, Chung S. Metastatic testis tumor presenting as gastrointestinal hemorrhage. J Urol. 2000; $164(5): 1655$.

10. Bosl GJ, Vogelzang NJ, Goldman A, Fraley EE, Lange PH, Levitt $\mathrm{SH}$, et al. Impact of delay in diagnosis on clinical stage of testicular cancer. Lancet. 1981 Oct 31; 2(8253):970-3.

11. Moul JW, Paulson DF, Dodge RK, Walther PJ. Delay in diagnosis and survival in testicular cancer: impact of effective therapy and changes during 18 years. J Urol. 1990;143(3):520-3. 